\title{
Erosion Protection by Polymer Additive
}

\author{
Mohamed Bader Algadwi', Emmanouil Spyropoulos², Bassim A. Nawaz \\ ${ }^{1}$ Tathbeet, \\ Khobar, Kingdom of Saudi Arabia \\ bader@tathbeet.net \\ ${ }^{2}$ Saudi Aramco \\ Dhahran, Kingdom of Saudi Arabia \\ emmanouil.spyropoulos@aramco.com; bassim.nawaz@aramco.com
}

\begin{abstract}
Surface erosion can exert a tremendous impact on natural resources and can cause serious economic losses because of blocked streams, degraded water quality, destroyed bridges and road rights-of-way, ruined spawning sites, lowered soil productivity, and property damage. Soil properties important to the evaluation of a site for its resistance to erosion include: particle size, permeability, water retention characteristics, compressibility, shear strength, void ratio or porosity, shrink-swell potential, liquid limit, and plasticity index. Soil erosion control techniques have the potential to reduce runoff and soil loss. Traditional stabilizers, such as lime cement, fly ash, and bituminous materials, etc., usually require a long curing time. Hence today polymer stabilizer is used extensively because of its stable chemical properties and shorter curing time. To evaluate the possibility of a sustainable erosion stabilization as alternative to the traditional concepts (e.g., marl), the role of polymer within the stabilization process is presented in this paper. Findings of numerous studies revealed that the addition of polymer to natural soils produced an improvement in their mechanical capacities and constructability's. For the mechanical capacities, enhancements in unconfined compressive strength, California bearing ratio, shear strength and, the strength of the stabilized soil is significantly increased both under wet and dry conditions. Moreover, it is cost and time effective compared with traditional methods. To further evaluate and confirm the sustainability and advantages of polymer use for erosion stabilization, projects undertaken in the Kingdom of Saudi Arabia - having the objective of increasing the resistance of soils to wind and water erosion - were further evaluated to identify the possibility of altering from the traditional erosion design into this more sustainable and economic solution.
\end{abstract}

Keywords: Water, Wind, Erosion Protection, Stabilization, Polymers, Non-metallic

\section{Introduction}

Geotechnical, construction, environmental and agricultural projects in different field and industries will benefit from a reliable soil stabilization technology. Several technologies have been tested and some have been implemented. The use of oil residue in soil stabilization has detrimental effects due to its environmental impact. Therefore, new methods and technologies were investigated. One of the most common methods is the use of marl soil. Polymer technology has been proven to be a reliable and more effective soil stabilizer in projects globally, and gaining more trust for use as the main soil stabilizer technology.

Numerous examples in literature discuss the polymer-amended soil benefits and extra mechanical enhancement that polymer adds to the soil; however, only a few studies highlighted the use of polymer in real-life projects. In this paper, a review of these studies will be summarized, and real-life projects will be discussed, including: soil enhancement, application method simplicity, and the economic benefit of the polymer application. Finally, this paper will compare marl technology to polymer technology from technical, environmental, and cost perspectives.

\section{Background}

Polymer-amended soil applications is a relatively new method to stabilize soils as a measure for erosion control. There are several studies that discuss soil enhancement introduced by polymer addition to soil. In the following sections a review of the previous research will be summarized to highlight polymer-amended soil performance, as well as the factors affecting the outcome of the polymer application. 


\subsection{Changes in Soil Imposed by Polymer Addition}

There are no chemical changes that will take place within the soil-polymer mixture. By introducing polymer to the soil, the polymer envelopes the soil particles, developing an interconnected bond between soil particles. This bond only exists when the polymer cures "dry" forming an active polymer membrane/film between soil particles. Consequently, producing an adherent soil particles "crust" out of loose soil. Hence, the changes imposed by the polymer addition to the soil are only physical changes. The research also highlighted the scanning electron microscope (SEM) images, as evidence of the physical changes [1].

The SEM images proved that the stability of the polymer-sand mixture and its strength is influenced by the polymer concentration and the soil's voids ratio. The polymer concentration is proportional to the stability of the mixture structure, while it is disproportionate to the soil voids ratio. The physical change introduced by the polymer addition was found to increase cohesion between soil particles, as well as increasing the stability of the formed polymer-soil layer or crust.

\subsection{Method of Stabilizing Soil Using Polymers}

Polymers can be used to enhance the soil using one of the following two methods:

\section{Mechanical method}

Polymer quantity is calculated based on the depth of the soil layer that requires stabilization, then the diluted polymer is mixed within the soil to produce a homogeneous mixture. For most applications, the produced mixture required compaction to increase its density [2].

$\underline{\text { Spraying method }}$

The diluted polymer will be sprayed on the soil surface, the solution should be calculated to fill the voids within the targeted layer depth [2].

Table 1: Comparison between mechanical and spraying method

\begin{tabular}{|c|c|c|}
\hline & Mechanical Method & Spraying Method \\
\hline Equipment & $\begin{array}{l}\text { Required a machine to mix the polymer } \\
\text { within the soil. A grader and spraying tanker } \\
\text { could be used }\end{array}$ & $\begin{array}{l}\text { Any mean could be used to evenly spray the } \\
\text { soil surface. Spraying nozzle or spraying } \\
\text { tanker could be used }\end{array}$ \\
\hline $\begin{array}{l}\text { Compaction } \\
\text { requirement }\end{array}$ & Require compaction in most of the cases & $\begin{array}{l}\text { If the native soil is not disturbed } \\
\text { compaction is not necessary }\end{array}$ \\
\hline $\begin{array}{l}\text { Polymer } \\
\text { quantity }\end{array}$ & Require high polymer quantity & Require low polymer quantity \\
\hline Main uses & $\begin{array}{c}\text { Soil with low permeability } \\
\text { (well-graded soil). } \\
\text { Required stabilization layer is more than } 50 \\
\mathrm{~mm}\end{array}$ & $\begin{array}{l}\text { Soil with moderate to high permeability } \\
\text { (poorly graded soil). } \\
\text { Required stabilization layer is less than } 50 \\
\mathrm{~mm}\end{array}$ \\
\hline
\end{tabular}

\subsection{Performance of Polymer-amended Soils}

The physical change introduced by the addition of polymer to the soil helps improve the structure of the soil, therefore a noticeable improvement of the soil's mechanical properties had been found by the addition of polymer even at small polymer concentration.

The tests that will be relevant to the soil ability to resist erosion are: Rainfall Erosion Test: ASTM D6459-19, Unconfined compressive strength: ASTM D2166, Direct shear: ASTM D3080. 


\subsubsection{Rainfall Erosion Test}

Wind and rain are the main reasons for soil erosion. The rain has a more severe effect on soil surface than wind. The research shows that the polymer quantity required to resist wind erosion is much less than the polymer quantity required to resist rain erosion.

Although the below Rainfall Erosion test result was conducted only 24 hours after spraying the diluted polymer, it shows shows a considerable enhancement on the soil rain resistance. At only $10 \%$ polymer concentration, the surface resistance changes from $29.8 \%$ ( $70.2 \%$ of the soil was eroded) to $88 \%$ (12\% of the soil was eroded) [3].

Table 2: Rainfall erosion test result [3]

\begin{tabular}{|c|c|c|c|c|c|}
\hline $\begin{array}{c}\text { Polymer } \\
\text { Concentration (\%) }\end{array}$ & $\begin{array}{c}\text { Polymer } \\
\text { Quantity }\left(\mathrm{g} / \mathrm{m}^{2}\right)\end{array}$ & $\begin{array}{c}\text { Dilution Water } \\
\text { Quantity }\left(\mathrm{g} / \mathrm{m}^{2}\right)\end{array}$ & $\begin{array}{c}\text { Spraying } \\
\text { Rate }\left(\mathrm{g} / \mathrm{m}^{2}\right)\end{array}$ & $\Delta \mathrm{m}(\mathrm{g})$ & *Ep (\%) \\
\hline 0 & 0 & 0 & 0 & 1404.2 & 70.2 \\
\hline 10 & 0.2857 & 2.7 & 3 & 260.3 & 12 \\
\hline 20 & 0.5714 & 2.4 & 3 & 110.8 & 5.5 \\
\hline 30 & 0.8571 & 2.1 & 3 & 22.5 & 1.1 \\
\hline
\end{tabular}

*Where Ep (\%) is defined as the erosion rate of soil; $\Delta \mathrm{m}(\mathrm{g})$ is the weight of dried soil.

\subsubsection{Unconfined Compressive strength (UCS)}

Many researchers reported the UCS values of tests completed with different soil types, mechanical and spraying sample preparations, and varying quantities of the polymer. All test results show considerable improvement in UCS value.

$\underline{\text { Sandy soil }}$

The value of UCS for sand soil (without polymer addition) cannot be determined, the reason being that the sand sample collapsed once the mold was removed. The value of the UCS for sand was considered zero.

Table 3: UCS test result [1]

\begin{tabular}{|c|c|c|c|c|}
\hline $\begin{array}{c}\text { Polymer } \\
\text { Concentration (\%) }\end{array}$ & $\begin{array}{c}\text { Dry Density } \\
\left(\mathrm{g} / \mathrm{cm}^{3}\right)\end{array}$ & Void Ratio & $\begin{array}{c}\text { Relative } \\
\text { Density (\%) }\end{array}$ & $\begin{array}{c}\text { Peak } \\
\text { Strength/Standard } \\
\text { Deviation }(\mathrm{kPa})\end{array}$ \\
\hline 0 & 1.4 & 0.89 & 21.05 & 0 \\
\hline 10 & 1.4 & 0.89 & 21.05 & $62.34 / 2.37$ \\
\hline 20 & 1.4 & 0.89 & 21.05 & $120.83 / 2.35$ \\
\hline 30 & 1.4 & 0.89 & 21.05 & $169.22 / 3.82$ \\
\hline 0 & 1.5 & 0.76 & 55.26 & 0 \\
\hline 10 & 1.5 & 0.76 & 55.26 & $78.15 / 3.28$ \\
\hline 20 & 1.5 & 0.76 & 55.26 & $197.96 / 3.63$ \\
\hline 30 & 1.5 & 0.76 & 55.26 & $238.65 / 3.22$ \\
\hline 0 & 1.6 & 0.65 & 84.21 & 0 \\
\hline 10 & 1.6 & 0.65 & 84.21 & $81.11 / 4.28$ \\
\hline 20 & 1.6 & 0.65 & 84.21 & $239.25 / 3.22$ \\
\hline 30 & 1.6 & 0.65 & 84.21 & $281.69 / 3.43$ \\
\hline
\end{tabular}

\section{Clayey Soil}


Table 4: UCS test result [3]

\begin{tabular}{|c|c|c|}
\hline $\begin{array}{c}\text { Polymer } \\
\text { Concentration }(\%)\end{array}$ & $\begin{array}{c}\text { Dry Density } \\
\left(\mathrm{g} / \mathrm{cm}^{3}\right)\end{array}$ & $\begin{array}{c}\text { USC/Standard } \\
\text { Deviation }(\mathrm{kPa})\end{array}$ \\
\hline 0 & 1.73 & $76.3 / 0.58$ \\
\hline 10 & 1.73 & $189.3 / 1.34$ \\
\hline 20 & 1.73 & $198.2 / 3.88$ \\
\hline 30 & 1.73 & $205.4 / 8.8$ \\
\hline
\end{tabular}

\subsubsection{Direct shear}

Shear strength is defined as the maximum resistance that a material can withstand when subjected to shearing. Cohesion is the component of shear strength of soil that is independent of inter-particle friction.

$\underline{\text { Sandy soil }}$

Table 5: Direct shear test result [1]

\begin{tabular}{|c|c|c|c|c|c|}
\hline $\begin{array}{c}\text { Polymer } \\
\text { Concentration } \\
(\%)\end{array}$ & $\begin{array}{c}\text { Dry Density } \\
\left(\mathrm{g} / \mathrm{cm}^{3}\right)\end{array}$ & Void Ratio & $\begin{array}{c}\text { Relative } \\
\text { Density }(\%)\end{array}$ & $\begin{array}{c}\text { Cohesion/Standard } \\
\text { Deviation }(\mathrm{kPa})\end{array}$ & $\begin{array}{c}\text { Angle of Internal } \\
\text { Friction/Standard } \\
\text { Deviation }(\text { degree })\end{array}$ \\
\hline 0 & 1.4 & 0.89 & 21.05 & $0.03 / 0$ & $25.66 / 0.35$ \\
\hline 10 & 1.4 & 0.89 & 21.05 & $2.31 / 0.13$ & $25.87 / 0.98$ \\
\hline 20 & 1.4 & 0.89 & 21.05 & $12.12 / 0.35$ & $28.44 / 0.31$ \\
\hline 30 & 1.4 & 0.89 & 21.05 & $25.67 / 0.94$ & $28.11 / 0.62$ \\
\hline 0 & 1.5 & 0.76 & 55.26 & $0.17 / 0$ & $26.16 / 0.3$ \\
\hline 10 & 1.5 & 0.76 & 55.26 & $17.4 / 0.46$ & $28.19 / 0.03$ \\
\hline 20 & 1.5 & 0.76 & 55.26 & $34.16 / 0.78$ & $32.17 / 0.89$ \\
\hline 30 & 1.5 & 0.76 & 55.26 & $50.58 / 1.21$ & $31.48 / 0.42$ \\
\hline 0 & 1.6 & 0.65 & 84.21 & $3.39 / 0.04$ & $29.27 / 0.26$ \\
\hline 10 & 1.6 & 0.65 & 84.21 & $29.81 / 1.23$ & $29.63 / 0.6$ \\
\hline 20 & 1.6 & 0.65 & 84.21 & $45.19 / 1.11$ & $32.56 / 0.67$ \\
\hline 30 & 1.6 & 0.65 & 84.21 & $82.3 / 1.79$ & $32.31 / 0.57$ \\
\hline
\end{tabular}

$\underline{\text { Clayey Soil }}$

Table 6: Direct shear test result [3]

\begin{tabular}{|c|c|c|c|}
\hline $\begin{array}{c}\text { Polymer } \\
\text { Concentration } \\
(\%)\end{array}$ & $\begin{array}{c}\text { Dry Density } \\
\left(\mathrm{g} / \mathrm{cm}^{3}\right)\end{array}$ & $\begin{array}{c}\text { Cohesion/Standard } \\
\text { Deviation }(\mathrm{kPa})\end{array}$ & $\begin{array}{c}\text { Angle of Internal } \\
\text { Friction/Standard } \\
\text { Deviation (degree) }\end{array}$ \\
\hline 0 & 1.73 & $56 / 1.36$ & $29.5 / 1.03$ \\
\hline 10 & 1.73 & $365.23 / 5.58$ & $29.1 / 1.16$ \\
\hline 20 & 1.73 & $373.17 / 18.63$ & $30 / 0.96$ \\
\hline 30 & 1.73 & $384.9 / 18.59$ & $30.1 / 1.20$ \\
\hline
\end{tabular}

\subsection{Factors Affecting the Result of Polymer Application}

The researches highlight the factors that affect the polymer-amended soil application. Below are the most common factors. 


\subsubsection{Polymer Type}

The most well-known and most-used polymers for the purpose of soil stabilization and erosion control are acrylic polymer, vinyl acetate polymer and butadiene-styrene polymer.

From the surface erosion resistance aspect, the three polymers perform similarly to a great extent, the main differences differences in performance that the butadiene-styrene polymer application causes a very small reduction in the stabilized layer permeability, while the acrylic polymer and vinyl acetate polymer cause a significant reduction in the stabilized layer permeability. In addition, butadiene-styrene polymer application produces a fixable polymer-soil mixture as opposed to the semi-rigid mixture produced by acrylic polymer and vinyl acetate polymer ([2], [4], [5]).

\subsubsection{Polymer Quantity}

The studies recommended that the polymer quantity and the amount of water should be calculated on the basis of the optimum moisture content. This will help to ensure that the soil will not reach its liquid limit [6].

\subsubsection{Environmental and Health Considerations}

Globally the environmental aspect plays an important role in project planning and implementation. The environmental factor must be considered during the selection of the polymer type.

According to the Agency for Toxic Substances and Disease Registry (ATSDR), Vinyl Acetate can cause health issues if not produced and applied in a controlled environment. The American Council of Government Industrial Hygienists (ACGIH) recommends that workers should not be exposed to more than $10 \mathrm{ppm}$ vinyl acetate in workroom air during an 8hour shift and over a 40-hour workweek. The components of the butadiene-styrene polymer are highly toxic.

According to the Agency for Toxic Substances and Disease Registry (ATSDR) the allowed limit of butadiene exposure is:

OSHA PEL (permissible exposure limit) $=1 \mathrm{ppm}$ (averaged over an 8-hour work shift)

OSHA STEL (short-term exposure limit) $=5 \mathrm{ppm}(15$-minute exposure)

The mixture itself, the butadiene-styrene polymer is not a hazardous substance or mixture. Out of the mentioned polymers, the acrylic polymers are very safe to produce and use.

The product in the market could be modified using other substances for enhancement purposes. The final product must be tested to ensure its compliance with the project requirements.

\subsubsection{Soil Characteristics}

The soil characteristics are interconnected, one property has an effect on the other properties and vice versa. Below are the main soil properties that were highlighted in the previous studies and their impact on the polymer-amended soil applications.

\section{Voids Ratio}

The voids ratio has a direct effect on the quantity of the diluted polymer required to stabilize the targeted depth. Soil with a higher void ratio requires more diluted polymer when compared to soil with a lower void ratio, to stabilize the same depth.

The soil void ratio must be considered to calculate the polymer quantity. In addition, natural moisture content should be studied during the diluted polymer quantity calculation. Saturated soil may prevent the sprayed diluted polymer from entering the soil voids.

\section{Permeability}

The coefficient of permeability is directly affected by the void ratio. The void ratio in polymer application addresses the required diluted polymer quantity, while the permeability could be used to determine the most suitable application method. For soil with a low coefficient of permeability, the mechanical method should be considered to be a suitable application method. 
In addition to the above, the soil's permeability influences the diluted polymer infiltration rate. That has a direct effect on the depth of the stabilized layer of soil.

\section{Case Study in Kingdom of Saudi Arabia}

Over the last few years, the polymer technology had been used in several projects for sand stabilization purposes in the Kingdom of Saudi Arabia (KSA). While the project management was performing quality assurance and quality control to ensure that the project's goals are met, it was also clear that investigations on testing polymer technology performance, capability, advantages, disadvantages, and economy must be considered.

\subsection{Projects Requirements}

Each project is unique when it comes to its requirement. All projects despite the differences in requirements will share the requirement of increasing the strength of the soil. Most project objectives can be categorized as shown:

\subsubsection{Erosion Control Application}

Developing a protective layer or crust that has high erosion resistance can prevent road collapse or pipeline exposure. For such requirements, the main objective of the polymer application is to create a film within the soil that creates a water-resistant layer or crust from $1 \mathrm{~cm}$ to $5 \mathrm{~cm}$ in thickness. The ability of the soil to withstand loads is not the primary driver for such applications.

Polymer applications can help to achieve project objectives related to soil stabilization, e.g., embankment stabilization, slopes or hillside reinforcement, road shoulder, and runway shoulder stabilization. Polymers can also help with dust control requirements in areas, e.g., helicopter pads, construction sites, solar farms, and stockpiles. The erosion control requirement is the focus of this paper.

\subsubsection{Load-bearing application}

Load bearing requirement can be divided into two main categories.

$\underline{\text { Human traffic }}$

It can be addressed separately from vehicle traffic. It was found that some of the erosion control applications develop a crust that is not damaged by human traffic.

$\underline{\text { Vehicle traffic }}$

Accidental animal traffic also can be added to the vehicle category due to the high pressure that animals can exert on the surface. While polymer applications can help strengthen the soil to bear more load, the load-bearing requirement will not be covered in this paper.

\subsubsection{Stabilization}

Even though soil stabilization itself is not a requirement, some of the project requirements can be achieved by using polymer-amended soil applications. Protecting highways, railways, and remote facilities from sand accumulation and stopping sand from creeping towards the highway or railway can be achieved using polymer applications.

While the same method of application could be used, the design of the application must be an output of studying the soil, location topography, and weather. Such requirements will not be covered in this paper.

\subsection{Application Implementation: real-life project example 3.2.1 Project description}

The selected project to be reviewed and discussed in this paper is a $16 \mathrm{~km}$ of a linear berm located at Saudi Arabia. The polymer application was introduced to replace $150 \mathrm{~mm}$ thick marl capping to stabilize the berm.

The two type of berms developed were the following.

Sandy area berm

The berm height was $450 \mathrm{~mm}$, and $5 \mathrm{~m}$ top width. The berm was covering an underground structure. Around $11 \mathrm{~km}$ of the total length of the project was located in the sandy area. 
$\underline{\text { Sabkhah area berm }}$

The berm height was $928 \mathrm{~mm}$, and $3.85 \mathrm{~m}$ top width. The berm was covering an underground structure. Around $5 \mathrm{~km}$ of the total length of the project was located in a sabkhah area.

\subsubsection{Polymer Quantities and Dilution Rate}

The polymer quantity should be calculated based on the following parameters.

Polymer product

Products available in the market do not have the same characteristics. The product supplier must conduct an internal test program to establish the exact performance of the polymer under question. Products can vary in solid content, which has a direct effect on the polymer quantity calculation and on the dilution ratio calculation.

The polymer used in this project is a type of styrene acrylate co-polymer with the following characteristics.

Table 7: Used polymer characteristic

\begin{tabular}{|c|c|c|c|}
\hline Appearance & Emulsion - viscous liquid & Vapor pressure & As water \\
\hline Colour & milky white & Freezing point/range & $0^{\circ} \mathrm{C}($ water $)$ \\
\hline Odour & $\begin{array}{c}\text { Mild - Slight ester and } \\
\text { ammonia }\end{array}$ & Boiling point/range & $100^{\circ} \mathrm{C}($ water $)$ \\
\hline Density & $1.04 \mathrm{~g} / \mathrm{cm}^{3}\left(23^{\circ} \mathrm{C}\right)$ & Evaporation Rate & $<1$ (water) \\
\hline Solid Contents & $50 \%($ approx. $)$ & Water solubility & $\begin{array}{c}\text { dilatable in all } \\
\text { proportions }\end{array}$ \\
\hline Viscosity & $2000-8000 \mathrm{cPa} . \mathrm{s}$ & Flashpoint & $\begin{array}{c}\text { The product is not } \\
\text { flammable }\end{array}$ \\
\hline pH & $7.5-8.5\left(20^{\circ} \mathrm{C}\right)$ & Flammability & not applicable \\
\hline Relative Density & $1.02-1.08($ water $=1)$ & Auto-ignition temp. & not applicable \\
\hline
\end{tabular}

The used polymer is free from heavy and toxic elements, it is nonflammable, UV stable, noncorrosive, and does not impose danger on the humans, animals nor plants.

Soil Characteristic

The soil type dictates the required quantity for the diluted polymer that required to fill the voids of the soil within the required stabilization depth.

The crust (stabilized soil layer) ability to resist erosion does not necessarily depend on the crust depth; however, it was one of the project requirements to achieve $12 \mathrm{~mm}$.

Sandy soil on the sandy area

Soil type: poorly graded sand

USCS Group symbol: SP

Table 8: Sandy Soil Characteristics

\begin{tabular}{|c|c|}
\hline Average soil porosity & $33.00 \%$ \\
\hline Average total voids & $3.300 \mathrm{Kg} / \mathrm{m}^{2} / \mathrm{cm}$ \\
\hline Average soil permeability & $0.00028025 \mathrm{~m} / \mathrm{s}$ \\
\hline Total required diluted polymer & $4.29 \mathrm{Kg} / \mathrm{m}^{2}$ \\
\hline Calculated polymer quantity & $0.344 \mathrm{Kg} / \mathrm{m}^{2}$ \\
\hline Calculated dilution ratio & $1: 12$ \\
\hline
\end{tabular}

Sabkhah soil on the sabkhah area

Soil type: Poorly graded sand with silt 
USCS Group symbol: SP- SM

Table 9: Sabkha Soil Characteristics

\begin{tabular}{|c|c|}
\hline Average soil porosity & $35.00 \%$ \\
\hline Average total voids & $3.500 \mathrm{Kg} / \mathrm{m}^{2} / \mathrm{cm}$ \\
\hline Average soil permeability & $0.0001413775 \mathrm{~m} / \mathrm{s}$ \\
\hline Total required diluted polymer & $4.55 \mathrm{Kg} / \mathrm{m}^{2}$ \\
\hline Calculated polymer quantity & $0.393 \mathrm{Kg} / \mathrm{m}^{2}$ \\
\hline Calculated dilution ratio & $1: 11$ \\
\hline
\end{tabular}

After counting for $0.75 \%$ average wastage, the polymer quantity $0.40 \mathrm{~kg} / \mathrm{m}^{2}$ was adapted for both sand and sabkhah berm. The 1: 13 (polymer: water) was adapted as the dilution ratio for the total length of the berm.

\subsection{Application Method}

The spraying application method was selected over the mechanical one. The spraying is ideal for applying polymer in linear projects in general. Because the method is easy and straight forward, it requires average skilled workers. The soil must be checked to ensure that spraying applications will be effective. Soil permeability is directly connected to the ability to use the spraying method. The soil must be permeable to a degree that will allow the solution of diluted polymer to infiltrate the soil and occupy the soil's voids. For the project in question, the spraying application was used as described below.

\subsubsection{Berm construction procedure}

The berm was constructed by moving the soil from the surroundings and used to make a pile of soil on top of the structure, the pile created as a strip along the structure. Then an excavator machine was used to shape the berm.

The shaped berm was then subject to compaction using the excavator bucket to apply pressure on the transferred soil. This task "semi-compaction" was intended to decrease the air between the soil particles, resulting in a substantial reduction in short-term soil settlement.

\subsubsection{Used Equipment for Spraying}

Water tank with an attached pump

Pump specification

Discharge: 500 700 L/min (Head: $30 \sim 50 \mathrm{~m}$, Steel spray nozzle)

Hoses

Forklift: used for handling polymer containers

\subsubsection{Application Execution}

Step one: polymer dilution with water

A $1,000 \mathrm{~L}\left(1.0 \mathrm{~m}^{3}\right)$ IBC container was used to accurately measure and transfer concentrated polymer into the water tank. The water tanker capacity was $14,000 \mathrm{~L}\left(14 \mathrm{~m}^{3}\right)$. To achieve the targeted dilution ratio, 1,000 $\mathrm{Kg}$ of the polymer was added to $13,000 \mathrm{Kg}$ of water.

Well water was used in the dilution process, it was free of dust, sand, and gravel. The well was located in the sabkhah area, which indicates the groundwater is mixed with seawater. Even though with high TDS (total dissolved solids), the water has no negative effect on the stability of the polymer nor the performance of the application in general.

Step two: spray diluted polymer

Spraying the diluted polymer is similar to spraying water. The area was divided based on the nature of the worksite and the capacity of the water tank. Dividing the area helped with control and measuring the actual spray rate. The diluted 
quantity was measured against the area to be sprayed per tank, then clearly marked. The workers used the spray nozzle to evenly spray diluted polymer by setting the spray nozzle on the shower between jet and mist spray.

\subsection{Application Conditions}

For the diluted polymer to infiltrate the top layer of the soil, the topsoil (5cm minimum) must be dry. In case of rain, the surface must be allowed to completely dry prior to application. Saturated or wet soil prevents the diluted polymer from occupying the voids of the soil as it will be fully or partially occupied with water. Also, the application should not be carried out during precipitation or if precipitation is forecast. In the case of a rainstorm, chances are that the newly sprayed polymer may be washed away. In such a case, the area must be inspected and assessed if it requires respraying.

During high wind conditions, the application is not recommended. High wind is defined as more than $20 \mathrm{~km} / \mathrm{hr}$., as the wind is strong enough that the sprayer cannot effectively aim on a spot on the surface, and if the application continues, it will result in wasted product.

\subsection{Curing Time}

The solution of diluted polymer infiltrates and fills the spaces between the soil particles. The polymer only forms a film within the top layer of the soil when the water evaporates. Then the film develops an interconnected bond between soil particles that binds them together, creating a crust. The formed crust increases the ability of the soil to resist erosion.

The crust will only be formed when the polymer cures. The curing of the polymer takes place when the following two events occur:

1. The used polymer consists of 50\% water, in addition, water is added during the dilution process. For the polymer to cure, complete evaporation of the water must occur first. When the water evaporates, it leaves only polymer particles, and these create a film that forms a matrix with soil particles.

2. Any type of polymer has a minimum film forming temperature (MFFT) that is the lowest temperature at which a polymer self-coalesces in the semi-dry state to form a continuous polymer film, which in turn acts as a binder. At temperatures at and above the MFFT of the polymer, the film is formed. At temperatures below its MFFT, the polymer cannot coalesce to form a continuous film and thus cannot bind itself. The MFFT for the used polymer was $16^{\circ} \mathrm{C}$. Soil temperature must be higher than $16^{\circ} \mathrm{C}$ for the polymer to cure and form a crust.

The actual time of curing was between two to five days, the variation in curing time due to weather fluctuations. In sunny and dry days, the crust will be formed in two days. But it will take more time for the crust to be formed, depending on how much precipitation the sprayed berm received.

\subsection{Results assessment}

The site was inspected after six months from application to assist the performance of the polymer-amended soil application.

\subsubsection{Crust formation}

Sandy area

The crust formed within the poorly graded sand in the sandy area had exceeded the required crust thickness, $12 \mathrm{~mm}$. Based on the actual sprayed rate the crust thickness found to be on the range between $20 \mathrm{~mm}$ to $50 \mathrm{~mm}$. The crust was also found to be rigid and not fixable, and would withstand human traffic. The top $2 \sim 4 \mathrm{~mm}$ of the crust has a high polymer concentration. The formation of the crust had made the surface almost impermeable.

$\underline{\text { Sabkha area }}$

The crust formed within the poorly graded sand with silt in the sandy area had achieved the required crust thickness, 12 $\mathrm{mm}$. Based on the actual sprayed rate the crust thickness was found to be in the range of $15 \pm 3 \mathrm{~mm}$. The crust also was found to be fixable and not rigid, and would not withstand human traffic. The top $2 \sim 4 \mathrm{~mm}$ of the crust had high polymer concentration. The formation of the crust had made the surface almost impermeable. 


\subsubsection{Stabilized Surface Integrity}

The crust formed by applying the polymer to the soil helped maintain the integrity of the constructed berms.

\subsubsection{Erosion Resistance}

A 6-month inspection shows that the crust formed by applying the polymer to the soil protected the berm surface from wind and rain erosion. The crust was found to be intact with minor damage in the sabkha area.

\section{Comparison between Marl Capping and Polymer Technology}

\subsection{Marl Capping}

Marl or marlstone is a calcium carbonate or lime-rich mud or mudstone that contains variable amounts of clays and silt. Marl is considered to be one of the four predominant types of soils found in Eastern Saudi Arabia (i.e., sand, marl, clay and sabkha). Marl soils are uniquely used in the construction of almost all types of road bases, embankments and foundations. Marl soil is a synonym of calcareous sediments. It has been defined by several researchers as a soil containing calcium carbonate $\left(\mathrm{CaCO}_{3}\right)$.

\subsection{Availability}

Marl is available in certain locations in the Eastern Province. Moreover, it required crushing, screening and transportation to the site. Because of the low quantity that can be moved per trip $\left(10 \mathrm{~m}^{3}\right.$ per trip $=700 \mathrm{~m}^{2}$ per $\left.150 \mathrm{~mm}\right)$, significant manpower hours are required for the transportation task. Therefore, it is advantageous if the marl quarry is near the worksite. Polymer can be transported in large quantities $\left(20\right.$ tons per trip =40,000 $\left.\mathrm{m}^{2} @ 0.5 \mathrm{~kg} / \mathrm{m}^{2}\right)$. Also, the polymer spraying application reduces the need to import soil to the worksite.

\subsection{Berm Construction Requirements}

While the marl capping layer is constructed over the sand berm and the compaction of the berm started after laying the marl layer, the polymer spraying application must be started only after the short-term settlement of the sand occurs. The excavator bucket should be used to apply pressure on the transferred soil. This task "semi-compaction" will decrease the air between the sand particles, resulting in a substantial reduction in short-term soil settlement.

\subsection{Application Method}

Marl capping is applied via the traditional method of building the berm using excavators. The method of applying marl capping follows: Lay marl soil on the constructed berm, compact/shape the marl soil using the excavator's bucket, spray water over the compacted marl

Applying polymer via spraying application is an easy and risk-free method. The spraying application does not require special equipment, as that used to spray water onsite can be used.

\subsection{Production/Application Time}

Assuming that the marl reached the worksite ready to be applied, the marl capping construction rate will be 250 linear $\mathrm{m}$ per day on average, the width of the berm does not have a noticeable effect on production. Polymer spraying application rate varies based on the tanker size and polymer spraying rate. Assuming the spraying rate is $0.50 \mathrm{Kg} / \mathrm{m}^{2}$ the following is the production expected. 
Table 10: Expected Polymer Production

\begin{tabular}{|c|c|c|}
\hline Tank size & Sprayed area & Notes \\
\hline $10 \mathrm{~m}^{3}$ & $4,000 \mathrm{~m}^{2}$ & $\begin{array}{c}\text { Average trip time (dilation + spraying) } 3 \text { hr. per trip, A tank } \\
\text { can do two trips per day }\end{array}$ \\
\hline $16 \mathrm{~m}^{3}$ & $6,400 \mathrm{~m}^{2}$ & $\begin{array}{c}\text { Average trip time (dilation + spraying) } 4 \text { hr. per trip, A tank } \\
\text { can do two trips per day }\end{array}$ \\
\hline $32 \mathrm{~m}^{3}$ & $6,400 \mathrm{~m}^{2}$ & Only one trip per day \\
\hline
\end{tabular}

Assuming the berm width is $7.5 \mathrm{~m}$ (berm width can be 5 to $7.5 \mathrm{~m}$ ), the spraying application production would be linear $850 \mathrm{~m}$ per day using $16 \mathrm{~m}^{3}$ tank.

\subsection{Strength}

Marl soil contains calcium carbonate and different quantities of fine soils like silt or clay. Fines partly dissolve when wet and the dissolved carbonate forms a glue between the particles when the water dries, which binds the particles together and creates a smooth and stiff surface. The unconfined compression strength (UCS) of the marl sample prepared at the dry side of the optimum moisture was found to be as small as $1975 \mathrm{kPa}$ and as high as $2307 \mathrm{kPa}$. Marl has the following lowgrade characteristics: Low dry density, poor strength when wetted, high water sensitivity, a drastic loss of bearing capacity occurs upon immersion in water.

Polymer-amended soil would improve soil compressive strength. The expected compressive strength is $2.2 \mathrm{MPa}$ equals to $2200 \mathrm{kPa}\left(\mathrm{KN} / \mathrm{m}^{2}\right)$. Considering that marl must be constructed at a $150 \mathrm{~mm}$ layer, marl will show higher stiffness at the early stage of the operation. But cracks and erosion will start to appear due to the marl's sensitivity to water.

\subsection{Sensitivity to Moisture/Durability}

Marl soil is highly sensitive to moisture. A noticeable loss of marl strength is due to high molding water content or immersion in water. Marl creates a smooth and stiff surface. Interchange between weather conditions (wet/dry) causes the marl to lose its surface agglutination. The marl surface then starts to lose its strength and became vulnerable to wind and rain erosion. Marl starts to erode after the first rainy season.

Polymer crust is water resistant, which is not dependent on crust thickness. Water is expected to run off the polymer crust if there is a slope or polymer crust that will retain the water till evaporation. Polymer crust is expected to last for three years without maintenance. It is recommended to carry out an annual inspection to ensure the crust is free from any damage.

\subsection{Environmental Factors}

Marl does not need a factory to be produced, saving energy, water, and fuel. A lot of equipment is required for harvesting and applying. When it rains, water dissolves the carbonates (responsible for agglutination of marl particles) the marl become soft and easily emit dust

Polymer-amended soil has the following positive effects on the environment: Safe with human animals and plants, free from heavy and toxic elements, non-flammable, does not require a lot of equipment for application. However, it requires a factory for production.

\section{Recommendation for Future Research}

The performance of the polymer application was directly affected by the soil type. More investigation is required to assist the use of polymer with several types of soil and different applications such as road construction, sand movement mitigation, soil improvement, liquification, settlement, and cavities. Also, finding the soil characteristics that have the most effect on the application will assist with the application design. The geotechnical and engineering communities have been researching and using polymer-amended soil applications for several purposes. There is no standard or reference that engineers and projects managers can refer to. 


\section{Conclusion}

The polymer-amended soil application had a noticeable improvement in the soil ability to resist wind and rain The polymer application can be used as alternative to traditional stabilization methods like marl. In comparison to the capping, the polymer-amended soil has a longer life span and lower cost. Investigating the soil type prior to the is essential, due to the variation of the outcome with the different soil types. When inspecting the selected project after application, it was found that the sand soil had shown more improvement that the sabkhah soil.

\section{References}

[1] Liu Jin, Bai Yuxia, Song Zezhuo, Lu Yi, Qian Wei and Kanungo Debi. (2018), "Evaluation of Strength Properties of Sand Modified with Organic Polymers" Polymers 10, no. 3: 287, [Online]. Available: https://www.mdpi.com/2073$\underline{4360 / 10 / 3 / 287}$

[2] Siddiqi, Razi A, Moore, John C. (1981). "Polymer stabilization of sandy soils for erosion control" Transportation Research Board, ISSN: 0361-1981, [Online]. Available: https://trid.trb.org/view/179484

[3] Song Zezhuo, Liu Jin, Bai Yuxia, Wei Jihong, Li Ding, Wang Qiongya, Chen Zhihao, Kanungo D. and Qian Wei. (2019). "Laboratory and Field Experiments on the Effect of Vinyl Acetate Polymer-Reinforced Soil" Applied Sciences, [Online]. Available: 9. 10.3390/app9010208.

[4] James Hanson, Gary Welling, Nazli Yesiller (2012). "Compaction and durability characteristics of polymer modified soils" 19th International Conference on Soil Mechanics and Geotechnical Engineering (Seoul), [Online]. Available: https://www.issmge.org/uploads/publications/1/45/06-technical-committee-17-tc211-16.pdf

[5] Mawat Mohammed and Ojaimi Mohammed (2019). "Enhancement of soil bearing capacity by using polymer emulsion"

[6] Chao Xing, Xueyan Liu and Kumar Anupam, "Response of Sandy Soil Stabilized by Polymer Additives," Open Access Journal of Environmental \& Soil Science, Lupine Publishers, LLC, vol. 1(3), pages 64-71, 2018. 